\title{
HAVING A SAY? THE POTENTIAL OF LOCAL EVENTS AS A TOOL FOR COMMUNITY ENGAGEMENT
}

\author{
NANCY STEVENSON
}

School of Architecture and Cities, University of Westminster, London, UK

\begin{abstract}
This article uses a case study to consider community event practices that include local people in discussions about the regeneration of their neighborhood and capture their responses to change. It is set in an area adjacent to the Queen Elizabeth Olympic Park, the site of London 2012 Olympic Games, and tracks the Hackney Wick Curiosity Shop (hereafter called the Curiosity Shop), an initiative that used events to engage diverse groups and develop shared experiences. The article explores the nature of these events identifying their potential and limitations. It identifies characteristics (conviviality, playfulness, creativity, and accessibility) that appear to create a powerful tool to involve local people, helping to develop a sense of community and producing locally generated place images. In this case their potential is not fully realized because the Curiosity Shop is situated within the complex context and turbulence associated with a mega-event and a major regeneration project where the market-led processes of reimaging and regenerating the area are dominant. This frenzied regeneration context is unusual, and it is argued the conviviality, playfulness, creativity, and accessibility identified here should be investigated further in a setting that is less turbulent to evaluate their effectiveness in engaging communities in debate, discussion, and collective reimagination of their localities.
\end{abstract}

Key words: Community events; Community engagement; Regeneration

Introduction

This article presents a longitudinal case study of the Hackney Wick Curiosity Shop, a program of locally envisaged activities that was devised to engage people in the creation of a community-led festival (the Hackney Wick Festival). The Curiosity Shop initiative used small-scale events to articulate locally generated stories, images, and responses to an urban regeneration project that was accelerated by a mega-event - the London 2012 Olympic Games (the Games). It involved local people in wider discussions about the transformation of their neighborhood, providing a platform for community activism. Much has been written about the implications of the Games for local people (including Boykoff \& Fussey, 2014; Cheyne, 2009; Davis \& Thornley, 2010; Poynter, 2009; Stevenson, 2016) 
and the context is discussed briefly in the literature review. However, this article is focused on the potential and limitations of local community events to engage people in debates about change rather than the changes brought about by the megaevent. This article aims to develop understanding of community-led events by exploring practices that draw together diverse members of the community and involve them in informal, convivial, and lighthearted discussions about development and change in the local area. In this article the term local community is defined geographically and includes people who live and work in an area just outside the Queen Elizabeth Olympic Park in East London. Its contribution is that it develops understanding of the possibilities of community event production as a way of engaging a wide range of people in imagining and shaping their neighborhoods.

\section{Events and Community Engagement}

Community events encompass "an interactive process that produces a sense of social reality for a 'located' group identity . . . that activates and is activated by ideas and issues about 'community' identity and 'place' that are already in circulation" (Duffey \& Mair, 2014, p. 54). They can intensify community networks and are conceptualized as temporary "bursts of community" coalescing groups within localities and creating powerful "moments of excitement and mobilization" (Brent, 2009 , p. 233). Drawing from Arendt's (1958) seminal work and conceptualization of power as "power to" do something, community events can be seen to have empowering qualities, enabling people to act in common with others and to create something together. Arendt's conceptualization is relational, communicative, and dynamic with power accumulating through shared practice or joint action. Community events bring people together, often attracting those who do not usually participate "in community and political activities" (Johnson, Currie, \& Stanley, 2011, p. 69). By providing time and space away from everyday activities, they can temporarily disrupt social relations, affording opportunities to meet people, share experiences, experiment, create, play, explore ideas, and learn together.

The socially empowering possibilities of community events are multiple: by encouraging people to develop and participate in activities together they offer "opportunities to regenerate the social life of local communities" (Waitt, 2008, pp. 515-516) and can create a sense of identity, loyalty, and placebased belonging (Boyle \& Hughes, 1991; Hughes, 1999; Quinn, 2005). They can improve networks and develop social capital (Arcodia \& Whitford, 2006; Derrett, 2003; Pernecky, 2013; Schulenkorf, Thomson, \& Schlenker, 2011; Stevenson, 2016) and be utilized to support strategies to combat alienation (Hughes, 1999). In multicultural and diverse neighborhoods, they can provide "opportunities where social differences can be transgressed or (re)negotiated" (Waitt, 2008, p. 527). Brent (2009) identified this in his recollection of a "community event that hid the divisions and problems, overlaid them with a warm sensation of togetherness for the $n i g h t$ " (p. 152, italics in original). This "sociality in practice" involves "people otherwise in conflict with one another" spending time together "for the sake of the children" (p. 152), and temporary masking of problems provides respite and opportunities for interaction. Community-led events "provide the potential to foster and engage disadvantaged communities" (Misener \& Mason, 2006, p. 48) "to build social capital and facilitate community change" (Rohe, 2004, p. 162). Despite their bounded time frame and atypical interactions they can create shared experiences, networks, learning, and memories that can have more lasting effects on people's everyday lives.

On the other hand, many researchers are critical that this type of event creates a temporary and illusory sense of community, providing a performance of equality and cohesion that fails to redress wider power structures and inequalities (Brent, 2009; Quinn, 2005; Rojek, 2013; Stevenson, 2016). Harvey (1989) and Waitt (2008) supported Foucault's (1979) contention that the exercise and acquisition of power are asymmetric, claiming that events do little to tackle the underlying causes of inequality and enact equitable change. This is illustrated in studies by Moukaffir and Kelly (2013) where local people are marginalized as a festival changes to accommodate its new international audience, and by Stevenson (2016), who illustrated that local events can lead to the uneven accrual of social capital, exacerbating existing inequalities within communities. These studies illustrate that 
local events can have unequal outcomes that reinforce the networks of power holders and elites.

\section{The Mega-Event Context}

Much has been written about the London 2012 Olympic Games, but in this article the interest is in the concerns of a local community on the boundary of the Olympic Park. This mega-event accelerated and reworked long-standing regeneration aspirations for East London by highlighting its strategic importance both to London and to the UK, privileging national and international interests over those of local people (Boykoff \& Fussey, 2014; Cheyne, 2009; Davis \& Thornley, 2010; Poynter, 2009; Stevenson, 2013). The Games project and its legacy were intended to be predominantly market driven, with the benefits from regeneration "trickling down" to the community (Allmendinger \& Haughton, 2009; Poynter, 2009; Stevenson, 2013). As the project developed aspirations changed and entrepreneurial values and practices were strengthened. The project was reframed to secure the expansion of London as a global city, diminishing the original social aspirations for the existing local communities surrounding the site (Davis \& Thornley, 2010; Stevenson, 2013). The agenda shifted from social inclusion and the aim to ensure existing communities benefited from regeneration in the area, to the creation of new balanced communities by attracting affluent newcomers (Greater London Authority [GLA], 2009; Stevenson, 2016; Watt, 2013). The aspiration for balanced communities had negative effects on lower income residents in and around the Olympic Park who were displaced by the demolition and redevelopment of social housing (Bridge, Butler, \& Lees, 2012; Cheyne, 2009; Stone, 2015; Watt, 2013).

Using a mega-event to accelerate regeneration presented considerable challenges to the local community, bringing uncertainties and providing opportunities and threats to people who lived and worked in the area. One immediate threat arose from the disruption and displacement associated with clearing the site and building the infrastructure to stage the Games. Local peoples' lives were relatively untouched by the employment opportunities associated with the Games development on their doorstep, but they experienced the negative aspects such as noise and pollution, loss of housing, road closures, and the introduction of parking restrictions (Cheyne, 2009; Horne \& Whannel, 2012; MarreroGuillamón, 2012; Porter, Jaconelli, Cheyne, Eby, \& Wagenaar, 2009; Poynter, 2009; Watt, 2013). Access restrictions also effected many local businesses that were cut off from their markets (Raco \& Tunney, 2010). During the Games planning process the need for quick decisions short circuited the discursive and democratic processes, which meant local people they had little opportunity to influence the proposals that had direct and permanent consequences for their lives (Cheyne, 2009; Stevenson, 2016). In this context, community event production increased as a way of people meeting to share stories and experiences, and in an attempt to develop their sense of community and articulate aspirations for their area as it regenerated and changed.

\section{Methodology}

The material presented in this article was collected as part of a longitudinal study carried out between 2008 and 2016, which investigated the local cultural activities and legacies arising from the London 2012 Olympic Games. The project was supported by research grants from the International Olympic Committee and the British Academy, and its inception coincided with the launch of the Cultural Olympiad 4 years before the Games and the first year of the Curiosity Shop. The end date was 4 years after the Games, which enabled consideration of the practices associated with the Curiosity Shop in the early legacy phase. A case study approach was adopted (Yin, 1994, 2003) and drew upon relevant material from a variety of sources, including interviews, observations of events and meetings, academic and "grey" literature including policy and practice documents. Initially interviews were conducted with an elected councilor and a member of a local community/arts organization to identify parameters for the wider study. Potential interviewees were selected by snowball sampling (Patton, 2002) and included residents, artists, arts organizations, local government officers, councilors, two vicars, and a head teacher. The case study focused on emerging practice at the local level and was grounded in the idea of phronesis aiming to develop "practical wisdom on how to address and act on social problems in a particular context" 
(Flyvbjerg, Landman, \& Schram, 2012, p. 1) and "knowledge that grows out of intimate familiarity with practice in contextualized settings" (Flyvbjerg et al., 2012, p. 2). Researching local perceptions of everyday practices involved deep engagement in the study area, which included regular attendance and observation of meetings and events, and some participatory observation in the field.

Data collection and analysis were influenced by grounded theory, which recognizes the interrelationship between peoples' perceptions, experiences, and action and the importance of their activities and interactions in shaping the world they live in. Grounded theory collects and analyses data simultaneously and provides a systematic procedure for collecting and analyzing qualitative data and furthermore investigates phenomena using the perspectives or voice of those studied (Glaser \& Strauss, 1967; Goulding, 2002; Stevenson, 2007; Stevenson, Airey, \& Miller, 2008). Interviews were semistructured, with opportunities for participants to ask questions and to raise issues that they thought were important. They were recorded and transcribed so that the researcher could reengage and reflect upon with their content, which enabled thoughts to develop and initial codes were devised that were used for analysis using NVivo. This open coding opened up the interview data by fragmenting it, identifying concepts, and using "constant comparison" (Goulding, 2002, p. 169) to explore similarities and differences. Memos were written to map ideas, refine concepts, identify relationships in the data, and then used to develop emerging concepts. These were analyzed in more depth and used to develop themes that are identified later in the article and compare interview material to wider experience and literature. Quoted material from the interviewees is identified throughout the article by their role or relationship to the neighborhood (project organizer, resident, council officer, etc.) and the date of the interview, which provides information about the source without revealing individual identities.

\section{The Case Study}

The study is based in Hackney Wick, a neighborhood in East London that is located just outside the Queen Elizabeth Olympic Park, the site of the London 2012 Olympic Games. It explores an initiative that uses community events to engage people in activities and discussions about their neighborhood and creates local community networks. The term "local community" is used to refer to the people who inhabit the area (varying degrees of living/working). There are complexities underlying this definition - for example its boundaries can be located on a map, but this spatial definition is only partial: Hackney Wick is also a mental construct reflecting "emotional boundaries" (Brent, 2009, p. 138), which is illustrated by some interviewees who inhabit a place called Fish Island in an adjoining borough but identify themselves within the Hackney Wick community. The community is made up of people from diverse social, economic, and ethnic backgrounds. Interviewees identify three dominant groupings that are identified as "old Wick" - made up of elders who are predominantly white and have lived in social housing in the area for many years; "new Wick" - a more ethnically diverse group who have moved in more recently and occupy some of the newer social housing; and "arty Wick"-artists and people who work in the creative industries, many of whom are recent arrivals and occupy private rented spaces in the area. The former two groups predominantly live in social housing estates and many suffer social and economic deprivation. Lacking social resources, such as confidence, networks, education, and experience, many have traditionally held low expectations of any benefits of working together. The creative community tend to be younger, are university educated, and digitally connected. They have skills, networks, and common interests, which enable them to communicate and engage together. These groups physically encounter one another regularly but often lead parallel lives with little to connect them other than their post code address (Councilor, 2008; Festival Organizer/vicar, 2009; Festival organizers/residents, 2009, 2012; Residents, 2009-2014). Notions of who is within and outside the community are fraught with ambiguities and Brent's (2009) conceptualization of community, as a process that is multiple, fluid, fragile, and created, is highly relevant.

\section{The Curiosity Shop}

The Curiosity Shop was developed in 2008 within the turbulent context associated with the construction of the Olympic Park and the wider 
regeneration project in the area. Its first iteration was a community engagement project that used a series of small-scale social events to bring people together to collect local memories and histories and involve them in a new community festival. The festival project had been envisioned by a group comprising people from a number of local institutions - the local school, church, community center, arts organization, and the doctors' surgery - all of whom saw it as a way of improving networks within the community and encouraging people to engage in discussions about the future of the area and to interact in its public spaces (Councilor, Curiosity Shop researcher, and Arts outreach worker, 2008 and 2009). The Curiosity Shop element of the festival project used small-scale events to develop dialogue across the diverse local community, encourage people to work together, and create activities and networks to support the community festival. It engaged with some existing tenants and community groups but also encouraged the involvement of people who were not part of these formal groups. People were approached at "the school gates, the caffs, the burger vans, the pharmacy, the doctors and places like that" (Curiosity Shop organizer, 2009) and were invited to share their experiences and stories in a series of events and workshops. Its first phase was funded by the Arts Council, commissioned by the local Arts organization called [Space] in 2008 and run by a local art/architecture practice called Public Works. It "used artists to tease the community aspect and engage at the right scale - small scale, to encourage things like story-telling, chutney making, singing old songs, cooking food, making cream teas, that sort of thing" (Festival organizer/vicar, 2009).

Our approach was about building networks ... we were really interested in having stepping stones leading up to the Festival . . . we developed very ad hoc informal events, about once every two weeks. And they became a little bit bigger and occurred about once every four weeks. There was not much budget, but enough to get those people involved ... and so they understood the Curiosity Shop idea and the Festival and could identify with that. (Curiosity Shop researcher, 2009)

During the Festival, these activities were drawn together and exhibited in a small structure providing a display space and hosting an exhibition including photos and recollections of the area (Project instigator [Space], 2009). This structure was used as a base from which to stage a range of events activities including talks, songs, games, a quiz, and short film screenings. These events aimed to engender a sense of community and encourage discussion about change in the neighborhood (Curiosity Shop researcher, 2009). By 2009 funding ceased for the project but much of its content was developed into a digital archive and the exhibition was displayed again at subsequent Festivals.

The second iteration of the Curiosity Shop began in 2011 when it became a pop-up visitor information center-presenting local attractions at a temporary festival and performance space called Folly for the Flyover (Create London, 2011). Since then the Curiosity Shop idea has been recycled and interwoven with other community development initiatives and has been used as a combined "archive and place for the dissemination of community ideas" (Project organizer, 2013) that has been displayed at events and festivals in the locality. It has been a bookshop, "drawing together a body of work of research, histories, and cultural production of Hackney Wick," (Project organizer, 2013), a "Surplus Shop" presenting ideas about recycling, an exhibition space, and a "Commons Shop" providing an archive of the "area's unofficial and 'minor' history through an eclectic collection of memories and memorabilia, oral history, songs and stories" (Queen Elizabeth Olympic Park, 2015). This iteration of the Curiosity Shop was locally led and presented local histories and ideas but was produced by a small group of people within the creative community and is criticized by eight interviewees for its selective engagement with "no targeting at all, to get people from the local estates involved" (Council employee, 2015).

Over the study period and in both iterations the Curiosity Shop used events to engage people through relatively informal social practices. These events supported discussion and creative engagement, relying on the voluntary contributions from a wide variety of people. They were not tightly choreographed, encompassing openness, playfulness (a sense of fun), and unpredictability that enabled people to become actively involved in the coproduction of events to develop and create a community narrative and response to change. In its first iteration 
the Curiosity Shop was a community development project with an internal focus. This created dynamic interactions between diverse communities by exploring and creating shared local histories with the community as participants and audience. In its second iteration it was reworked by members of the creative community into a series of pop-up installations, illustrating local narratives and responses to urban change to a wider audience. It evolved into an exploratory event space that provided an informal archive of local ideas and collaborations, becoming more engaged in debates about sustainability, targeting "those people that want to get hands-on involved" within the local community (Project organizer, 2013). This deeper intellectual engagement and interrogation of urban change narrowed its reach and is criticized by some interviewees.

\section{What Were the Positive Outcomes?}

The Curiosity Shop was community led and the first phase had an inclusive framing. It actively engaged people who were marginalized in debates about the future of their rapidly changing neighborhood, providing opportunities for less powerful communities within local social housing estates to voice their ideas and opinions. It was part of a process that developed and articulated local values, creating dialogue with neighbors, community networks, and locally produced images of the neighborhood. There was a sense of power associated with these celebrations that provided a feeling of engagement in regeneration debates. Its ability to articulate local aspirations and enable the development of community networks will be considered in more depth below.

\section{Providing a Process to Articulate Locally Generated Aspirations}

Both phases of the Curiosity Shop presented local perspectives, providing an alternative to the megaevent story, which portrayed the area as an industrial wasteland, a place of social isolation and exclusion. Events were used a mechanism to explore and exhibit alternative stories and visions for the neighborhood in a locally led process that highlighted its people and positive aspects. Initially a combination of memory and play were used to draw together and present recollections of the past, illustrating the strengths of the community and articulating what was important and should be protected as the area changed. The active processes associated with generating local place images and "imagining different outcomes" were both "relevant and necessary for residents" (Resident, 2012) as decisions were made about the development of the Olympic Park and its surroundings. The local events format provided the opportunity to develop an understanding across different communities who experienced feelings of "disempowerment" and "dispossession" (Residents, 2009-2012) associated with wider changes affecting their locality, and enabled people to develop counter narratives to powerful negative or partial images of the area. These events provided a mechanism to articulate what was valuable to local people, and to creatively and actively imagine a better future that encompassed the existing community.

\section{Enabling the Community to Develop Networks and Connect to Other Initiatives}

In the complex and dynamic environment of a mega-event and a major regeneration project there were many processes at play, funding opportunities and new initiatives emerging. The Curiosity Shop events started to connect into what were:

\footnotetext{
Initially . . . a programme of events leading up to the Festival, which involved the public ... but as people became engaged with Curiosity Shop they became by default engaged with the Festival. It was an interesting vehicle, for achieving one aim, but at the same time developing a lot of other connections. (Project instigator [Space], 2009)
}

The community development aspects of the Curiosity Shop, and the Festival to which it contributed, enabled a robust committee structure to emerge across diverse residential communities. Networks were created that started to connect to other initiatives and the Festival committee structure enabled the community to access $£ 1$ million Big Lottery funding. Their use of events as a mechanism for community engagement was identified as a particular strength and a reason why they were selected:

A broad range of organizations in Wick ward were invited to a meeting by the people from the 
Big Local (Lottery Funding) . . . the Wick Festival organization was chosen - they were small, broadly focused and had effectively used a variety of different tools to engage with people. (Council employee, 2012)

Thus, it can be seen that despite some concerns that the second phase of the Curiosity Shop was less inclusive, it is evident that the learning, structures, and practices that developed throughout the project influenced and informed local people, enabling them to engage in discussions about the neighborhood, articulate aspirations, and bid for other funding and projects. The community development aspect has not been lost and many aspects have migrated to other initiatives. Organizing events and then the Festival provided experience, confidence, and clear decision-making structures, enabling the community win Lottery funding for the Wick Award. This project is ongoing and enables local people to "come up with ideas and improve the area and do something which is locally based ... giving them more autonomy and more power to guide the nature of their neighborhood" (Council employee, 2013). It supports and funds a variety of locally envisaged and inclusive youth and community projects and community events within the local housing estates (Wick Award, http://www. wickaward.co.uk/about).

\section{The Potential of These Community Events}

The practices associated with these community events appear to have considerable potential as a mechanism to include diverse local communities in discussion about change. They are convivial, playful, accessible, and involve people participating, making, and doing together. These aspects are now considered in more detail.

Event production is a convivial process involving the sharing of ideas, experiences, and expertise through social interaction as people connect through collective action, and envisage, plan, and learn together. Organizing and participating in community events engages people in dialogue over time involving negotiation, collaboration, and the development of networks within and between communities (Harvey, 1989; Stevenson, 2016; Waitt, 2008). The events associated with the Curiosity Shop are small scale, repeated often, encourage conversations and "collaborations that wouldn't otherwise, normally happen" (Festival participant/ artist, 2014), creating shared experiences across diverse communities. This example of "sociality in practice" (Brent, 2009, p. 152) provides opportunities for discussion and interaction and develops connections that outlast the event itself. This can be seen informally as people start to meet and talk (Residents 2010-2016) and formally as the Curiosity Shop networks merge into the Festival organizational networks and evolve into a structure to enable the community to bid for the Wick Award. Interviewees contrast the events approach with more formal mechanisms that are used to discuss regeneration issues with local people which are described as "very much "them and us" (Councilor, 2008). "PowerPoint presentation and 'suits' - pinstripes in one corner and 'rent-a-mouth' protesters in another, without any proper dialogue. And both sides with an interest in being angry and annoyed with each other" (Resident, 2009).

The playfulness associated with the Curiosity Shop events also enables people to step away from the mundane activities associated with day-to-day life, to do something celebratory and creative. For example, some events encourage the elder community to share recollections about the old times, and engage newer members of the community in stories, songs, and quizzes. The convivial atmosphere of these social events-with music, food, activities, and games - is used to draw people together and encourage a light-hearted engagement in the debates about the opportunities and challenges faced as the area regenerates. Creative and artistic practices are employed to draw out and collate ideas into exhibitions, talks, and activities. These events provide opportunities to meet neighbors, share ideas, and have fun, tapping into an aspiration to create a sense of community and to imagine a more inclusive form of regeneration. Beneath the fun and the sociability are the opportunities for explorations and discussions around what matters within the community and to develop ideas and articulate aspirations for the future for the area.

These events create a time and space for enjoyment, exploration, and experimentation and potential to engage with and influence the debates about the regeneration of the area. The process of participating, making, and doing together involves 
discussion and can be a used as a mechanism to help to articulate and develop a community response to change. Events provide "space and enough opportunities, enough time to open things out, to diffuse the froth bit and get to some of the issues" (Resident, 2009). It makes locals "feel more comfortable to come forward with their ideas . . . as they choose to do ... to design it their own way (Councilor, 2008).

The Curiosity Shop events are developed locally by people who have a stake in the area and are affected by the outcomes of change. They use straightforward language, face-to-face contact, and activities to enable people to understand and contribute to them. This means that ideas and outcomes are accessible, "people talk about them ... they understand them" (Festival organizer/resident, 2010) and are circulated locally in a process that connects them to other local events and initiatives in the area. The community event format provides opportunities for experimentation, responds to the wider changes within the area, and had a role in instigating small changes within the community. The process is cumulative - these small-scale community events connect people to the Festival and then to the Wick Award. Several interviewees contrast the impacts and implications of those projects that were developed within the community and those that are conceived outside the area. Externally led projects are seen to lack reciprocity and to be disconnected, with benefits accruing to people outside of the area. Interviewees say that they often they use processes and "language" that no one understands, which means that people do not engage. One festival organizer and local resident explains "If you really want to engage the community you've got to say it in a different way. It has to relate to them or they won't engage" (Festival organizer, 2010).

The possibilities associated with these local events are derived from their ability to involve a wide group of people in discussions about what they value in the area and what they envisage for its future. They provide a playful form of community engagement and offer considerable potential as a mechanism to develop a more inclusive approach to regeneration. Developed within the community, they articulate and celebrate what is important, communicating ideas in an accessible way, engaging people, and enabling them to express themselves. Their playfulness and creativity hold considerable potential-creating and participating in something that is enjoyable enables people to step away from their day-to-day roles and activities. Festivity enlivens the locality and creates social possibilities, opportunities for dialogue, and shared experience. In this case it provides a basis for network formation, experimentation, exploration of funding sources, and reworking ideas for different agendas. These qualities have the potential to create resilience within the community.

\section{Limitations}

The limitations of locally envisaged events associated with the Curiosity Shop are apparent in the context of a fast moving, market-led, mega-event regeneration context (Boykoff \& Fussey, 2014; Cheyne, 2009; Davis \& Thornley, 2010; Haughton \& Allmendinger, 2015). This process is described as a regeneration "juggernaut" (Councilor, 2009) speeding through the area. In this setting local decision makers feared they would be excluded from decision making if they were not on board and felt under pressure to make quick decisions and support development proposals (Councilors, 2008, 2012). Thus, the Curiosity Shop events could do little to resolve community concerns or address the economic inequalities that arose as the area changed. On one hand these events were meaningful to people, addressed some local-level needs, offered people in the community the potential to engage together, and developed a community infrastructure (the Festival Steering Group), which enabled them to access Lottery Funding. On the other there is little evidence that they influenced wider processes underpinning change in the area, improved the social circumstances of more than a handful of entrepreneurial individuals within the community, and created redistributive or socially just outcomes in the wider regeneration process. The limitations of the Curiosity Shop events to enact change is attributed to the absence of strong policies to ensure socially just outcomes and the political will to translate community ideas into practice (Council employee, 2012, 2014; Councilor, 2014; Curiosity Shop project organizer, 2013; Festival organizer, 2009; Vicar, 2015). The context is one of 
market-led regeneration directed by decision making and investment from outside the area and thus the inclusive potential of these small scale events is inhibited. Despite there being "a lot of willingness, in Hackney Wick for individuals to come together, to have their say, to state how they'd like to shape their neighbourhood - the strategic oversight to enable them to do this is missing" (Council employee, 2012).

There are also limitations associated with the inequalities and the asymmetries of power (Foucault, 1979) within the community, which became apparent as the project evolved and drew more heavily from the creative community. This imbalance and its effect is identified in other studies (including Misener \& Mason, 2006; Stevenson, 2016; Waitt, 2008) and reflects the concerns that those who have fewer resources tend to participate less and derive least from these events. The creative community are the most vocal and active in many local initiatives and concerns about this are expressed repeatedly during the interviews:

I feel some disquiet that quite often events or discussions are dominated by a large number of young white artists who come out of art college and have recently moved there. I didn't quite see the same level of engagement with the estate communities. It was incredibly hard to engage people who don't know about the money. . . . It's these major estates that have got real issues because that's where the deprivation statistics come from and why the money was given to this area. (Interview with council employee, 2013)

The creative community is articulate and has many shared aspirations and networks. Therefore, it is unsurprising that they are more dominant in discussions about regeneration and what local people want in their future. Lower participation by the estates communities is attributed to feelings of alienation and position outside dominant community groups within the area. Furthermore, this group has complex and diverse social characteristics, networks, and needs. In this context it is difficult to identify a clear and universally accepted set of aspirations for the area and to communicate these to policy makers (Residents, Festival organizers, 2009, 2012). However, it should be noted that there have been efforts to counter this problem through the projects and events that are funded through the Wick Award to ensure that projects and events reflect a broad range of needs within the estates' communities (Community development worker, 2017). The learning and some networks from the Curiosity Shop and Festival have persisted and events continue to play a role in community engagement in the neighborhood.

The community events considered here make an important contribution but are marginal to the main regeneration project, small scale, minimally or unfunded, and organized at a local level. Thus, they are unable to resolve the fundamental inequalities within the community, and between the communities and policy makers and investors in the area. Their socially inclusive potential is not realized as more powerful processes associated with marketled regeneration are at work (Harvey, 1989; Porter et al., 2009; Porter \& Shaw, 2009; Poynter, 2009; Stevenson, 2013; Watt, 2013). Although community events provided a mechanism for people to discuss, question, and respond to some aspects of the change in the area (Boykoff \& Fussey, 2014; Stevenson, 2016; six interviewees), in the context of this study they have not had the power to resolve the major concerns about the implications of gentrification and the displacement of poorer local residents from the area (Boykoff \& Fussey, 2014; Stone, 2015; 18 interviewees).

\section{Conclusion}

This article explores the potential of community events to bring people together and involve them in the debates about the future of their neighborhood. It illustrates a story about how an initiative is conceived, develops, and then coalesces with and informs other projects and programs as the area changes. The study has some unusual features-it is set within the complex context of an Olympic regeneration project that accelerates the pace of change and significantly reduces the scope for local action. However, despite its difficult and complex context, this event-based initiative is successful in engaging a wide group of the local population in discussions about change.

Two themes emerge in the stories told by interviewees; one illustrates the potential of the small events associated with the Curiosity Shop to develop a sense of community and facilitate the 
creation of local resources, networks, and community decision-making structures. By linking to other initiatives, these events have a cumulative impact and provide practical support and a voice to people in the area. Their outcomes are small scale but nevertheless important, bringing people together, facilitating interaction, and developing connections within and across diverse community groups, and between communities and decision makers. In this rapidly regenerating place, they provide occasions for people to discuss, explore, and engage in the opportunities and challenges associated with change. This story is used to identify characteristics - conviviality, playfulness, creativity (making and doing), and accessibility - that "offer opportunities for linking up, for exploring ideas, for thinking bigger and differently" (Project instigator [Space], 2009). These characteristics appear to offer possibilities for inclusive local engagement in discussion about neighborhood change/regeneration.

The second identifies the limitations of these events as a mechanism to include people in discussions about regeneration associated with a mega-event. This story focuses more on contextual issues arising around the mega-event, the pace and nature of change, limited consultation, and uneven power relations within the community. It highlights the implications of the unique turbulence, tight deadlines, political obligations, economic circumstances, and media attention that arise in a mega-event setting. The apparent contradictions within these stories are a result of the incredibly complex context of the study and the disconnect between local aspirations and the market-led processes associated with the mega-event phase of a major regeneration project.

This article is motivated by a wish to develop understanding of the capacity of community events to enhance community engagement in local decision making. It illustrates that the combination of conviviality, making/doing, and play have considerable potential as a mechanism to engage a wide range of people within diverse local communities and support the development of a more "discursive public realm within which people can argue about what their city is and should be" (Healey, 2002, p. 1779). The events presented here appear to have inclusive and democratic possibilities enabling less engaged parts of the community to take part in discussions about regeneration, articulate what is important to them, and develop community networks. In this case they do not have the power to tackle the wide underlying causes of inequality; however, they create shared experiences and conversations, and support the development of networks that enable people to generate locally produced narratives and aspirations for change. Furthermore, their discursive and connective aspects offer opportunities to decision makers who are genuinely seeking more socially just and sustainable outcomes as they regenerate their areas. Further work is needed to explore how events might be used as part of a strategy to include local people in decisions about the future of their areas. Specifically, it would be useful to explore local events and community development within a less turbulent setting and in other regeneration contexts in order to ascertain how to develop their untapped participatory and inclusionary potential.

\section{References}

Allmendinger, P., \& Haughton, G. (2009). Soft spaces, fuzzy boundaries, and metagovernance: The new spatial planning in the Thames Gateway. Environment and Planning A, 41(3), 617-633.

Arcodia, C., \& Whitford, M. (2006). Festival attendance and the development of social capital. Journal of Convention \& Event Tourism, 8(2), 1-18.

Arendt, H. (1958). The human condition. Chicago, IL: The Chicago Press.

Boykoff, J., \& Fussey, P. (2014). London's shadow legacies: Security and activism at the 2012 Olympics. Contemporary Social Science, 9(2), 253-270.

Boyle, M., \& Hughes, G. (1991). The politics of the representation of 'the real': Discourses from the Left on Glasgow's role as European City of Culture, 1990. Area, 23(3), 217-228.

Brent, J. (2009). Searching for community. Bristol, UK: The Policy Press.

Bridge, G., Butler, T., \& Lees, L. (2012). Mixed communities, gentrification by stealth? Bristol, UK: The Policy Press.

Cheyne, J. (2009). Olympian master planning in London. Planning Theory and Practice, 10(3), 404-408.

Create London. (2011). Folly for a flyover. Retrieved from http://createlondon.org/event/2011-create-art-award/

Davis, J., \& Thornley, A. (2010). Urban regeneration for the London 2012 Olympics: Issues of land acquisition and legacy. City Culture and Society, 1(2), 89-98.

Derrett, R. (2003). Making sense of how festivals demonstrate a community's sense of place. Event Management, 8(1), 49-58.

Duffey, M., \& Mair, J. (2014). Festivals and sense of community in places of transition: The Yakkerboo Festival, 
an Australian case study. In A. Jepson \& A. Clarke (Eds.), Exploring community festivals and events (pp. 54-65). Abingdon, UK: Routledge.

Foucault, M. (1979). Discipline and punish. New York, NY: Vintage.

Flyvbjerg, B., Landman, T., \& Schram, S. (2012). Real social science-Applied phronesis. Cambridge, UK: Cambridge University Press.

Glaser, B., \& Strauss, A. (1967). The discovery of grounded theory: Strategies for qualitative research. London, UK: Weidenfeld and Nicholson.

Goulding, C. (2002). Grounded theory: A practical guide for management, business and market researchers. London, UK: Sage.

Harvey, D. (1989). The urban experience. Oxford, UK: Blackwell.

Haughton, G., \& Allmendinger, P. (2015). Fluid spatial imaginaries: Evolving estuarial city-region spaces. International Journal of Urban and Regional Research, 39(5), 857-873.

Healey, P. (2002). On creating the 'City' as a collective resource. Urban Studies, 39(10), 1777-1792.

Horne, J., \& Whannel, G. (2012). Understanding the Olympics. Abingdon, UK: Routledge.

Hughes, G. (1999). Urban revitalization: The use of festival time strategies. Leisure Studies, 18(2), 119-135.

Johnson, V., Currie, G., \& Stanley, J. (2011). Exploring transport to arts and cultural activities as a facilitator of social inclusion. Transport Policy, 18, 68-75.

Marrero-Guillamón, I. (2012). Olympic state of exception. In H. Powell \& I. Marrero-Guillamón (Eds.), The art of dissent-Adventures in London's Olympic state (pp. 20-29). London, UK: Marshgate Press.

Misener, L., \& Mason, D. (2006). Creating community networks. Can sporting events offer meaningful sources of social capital? Managing Leisure, 11(1), 39-56.

Moufakkir, O., \& Kelly, I. (2013). Peace through tourism a sustainable development role for Events. In T. Pernecky \& M. Luck (Eds.), Events, society and sustainability-Critical and contemporary approaches (pp. 130-150). London, UK: Routledge.

Patton, L. (2002). Qualitative research and evaluation methods (3rd ed.). Thousand Oaks, CA: Sage.

Pernecky, T. (2013). Events, sociology and sustainability: Five propositions. In T. Pernecky \& M. Luck (Eds.), Events, society and sustainability-Critical and contemporary approaches (pp. 15-29). London, UK: Routledge.

Porter, L., Jaconelli, M., Cheyne, J., Eby, D., \& Wagenaar, H. (2009). Planning displacement: The real legacy of major sporting events. "Just a person in a wee flat": Being displaced by the Commonwealth Games in Glasgow's East End. Olympian Masterplanning in London closing ceremonies: How law, policy and the Winter Olympics are displacing an inconveniently located low-income community in Vancouver. Commentary: Recovering public ethos: Critical analysis for policy and planning. Planning Theory \& Practice, 10(3), 395-418.

Porter, L., \& Shaw, K. (2009). Whose urban renaissance? An international comparison of urban regeneration strategies. London, UK: Routledge.

Poynter, G. (2009). The 2012 Games and the reshaping of East London. In M. Imre, L. Lees, \& M. Raco (Eds.), Regenerating London: Governance, sustainability and community in a global city (pp. 132-150). Abingdon, UK: Routledge.

Queen Elizabeth Olympic Park. (2015). The Wick Common Shop. https://www.queenelizabetholympicpark.co.uk/whatson/events/2015/02/the-wick-common-shop

Quinn, B. (2005). Arts festivals and the city. Urban Studies, 42(5/6), 927-943.

Raco, M., \& Tunney, E. (2010). Visibilities and invisibilities in urban development: Small business communities and the London Olympics 2012. Urban Studies, 47(10), 2069-2091.

Rohe, W. M. (2004). Building social capital through community development. Journal of the American Planning Association, 70(2), 158-164.

Rojek, C. (2013). Event power (how global events manage and manipulate). London, UK: Sage.

Schulenkorf, N., Thomson, A., \& Schlenker, K. (2011). Intercommunity sport events: Vehicles and catalysts for social capital in divided societies. Event Management, 15(2), 105-119.

Stevenson, N. (2007). Researching the experience and perspectives of tourism policy makers. In D. Airey \& J. Tribe (Eds.), Developments in tourism research (pp. 185-197). Oxford, UK: Elsevier.

Stevenson, N. (2013). The complexities of tourism and regeneration: The case of the 2012 Olympic Games. Tourism Planning \& Development, 10(1), 1-16.

Stevenson, N. (2016). Local festivals, social capital and sustainable destination development: Experiences in East London. Journal of Sustainable Tourism, 24(7), 990-1006.

Stevenson, N., Airey, D., \& Miller, G. (2008). Tourism policy making: The policymakers' perspectives. Annals of Tourism Research, 35(3), 732-750.

Stone, J. (2015). Why march for homes? Because the housing crises goes far beyond us Focus E15 mums. Guardian. Retrieved from http://www.theguardian.com/commentisfree/2015/jan/31/march-for-homes-focus-e15mums-london-homelessness-priced-out-area

Waitt, G. (2008). Urban festivals: Geographies of hype, helplessness and hope. Geography Compass, 2(2), 513-537.

Watt, P. (2013). 'It's not for us.' City: Analysis of Urban Trends, Culture, Theory, Policy, Action, 17(1), 99-118.

Yin, R. K. (1994). Case study research: Design and methods (2nd ed.). Newbury Park, CA: Sage Publications.

Yin, R. K. (2003). Applications of case study research. Thousand Oaks, CA: Sage Publications. 